\title{
Experimental Investigation on Mechanical Properties of Part Fabricated by Wire Arc Additive Manufacturing Process
}

DOI:10.36909/jer.ICMMM.15809

\author{
Vivek Kumar P*, Soundrapandian E, Jenin Joseph A, Kanagarajan E \\ Department of Mechanical Engineering, Bannari Amman Institute of Technology, \\ Sathyamangalam, Erode, 638401. \\ * Corresponding Author: vivekkumar@bitsathy.ac.in
}

\begin{abstract}
Additive manufacturing process is a method of layer by layer joining of materials to create components from three-dimensional (3D) model data. After their introduction in the automotive sector a decade ago, it has seen a significant rise in research and growth. The Additive manufacturing is classified into different types based upon the energy source use in the fabrication process. In our project, we used self-build CNC machine that runs MACH3 software, as well as the MACH3 controller is used to control the welding torch motion for material addition through three axis movement (X, Y and Z). In the project we used ER70 S-6 weld wire for the fabrication and examined its microstructure and mechanical properties. Different layers of the specimen had different microstructures, according to microstructural studies of the product. Rockwell hardness tester used for testing hardness of the product. According to the observation of the part fabricated components using the Wire Arc Additive Manufacturing process outperformed the mechanical properties of mild steel casting process. The product fabricated by Wire Arc Additive Manufacturing process properties is superior to conventional casting process.
\end{abstract}

Keywords: Microstructure, hardness, CNC 3 axis, Additive manufacturing (AM), mach3, weld wire ER70 S-6. 


\section{INTRODUCTION}

This review paper talks about the mechanical properties which are tested and material properties and defects [1]. It is the coat modeling and the sensitivity analysis of the wire arc additive manufacturing. The full process is chain modeled and tool path based on the deposition cost employed [2]. The Deposition efficiency is calculated. Through this it has high stability, surface quality was improved, coefficient of utilization of material [3]. Taguchi Method is a process/product optimization method that is based on 8-steps of planning, conducting and evaluating results of matrix experiments to determine the best levels of control factors [4]. Some micro structural characterization such as ferrite, bainite, marten site all is performed by the scanning electron microscopy [5]. This photographic apparatus is used to measure the dimensions of the objects in a rotating stage [6]. During such bead-on-bead deposition, a geometrical model proposed to predict the layer thickness of a given layer showed good correlation with experimental data [7]. The NC program for near-net shape building is created by custom software, the intricacies of combining an arc welding unit with a CNC milling machine [8]. However, complete automation entails trade-offs in geometry and material quality [9]. With the High pressure interposes rolling gives micro structural benefits. [10]. The microstructure shows the uncontrolled grain size during the process induced in the tensile residual stress [11]. The SW reduces the product's tensile properties and fatigue life by acting as a stress raiser [12]. Using a scanning electron and optical microscope, the broken faces and microstructure were examined [13]. In the microscope, they saw the heat-affected zone of material. the result of the microstructure was labelled, phase structure and micro hardness analysis [14]. The aim of this research is to look at existing 3D printing techniques for magnesium and provide recommendations for the best additive practices for these alloys [15]. The aim is to show how the position inside the manufactured wall portion affects 
microstructure and mechanical properties. In the near-substrate zone [16]. The effects of building techniques such as oscillation, parallel, and weaving on bead form were investigated, as well as process parameters. [17]. Face milling is used to extract scales and scallops and ensure Z-accuracy in each layer created by overlapping beads. [18]. Cooling rates were discovered to be an important indicator of these saturation limits, assisting in process control [19]. In the formation of the single bead and overlapping multi beads in this paper to individual influence of the size of the filler wire, speed of the wire and the torch [20].

\section{MATERIALS AND PARAMETERS \\ Metal Inert Gas (MIG) Machine}

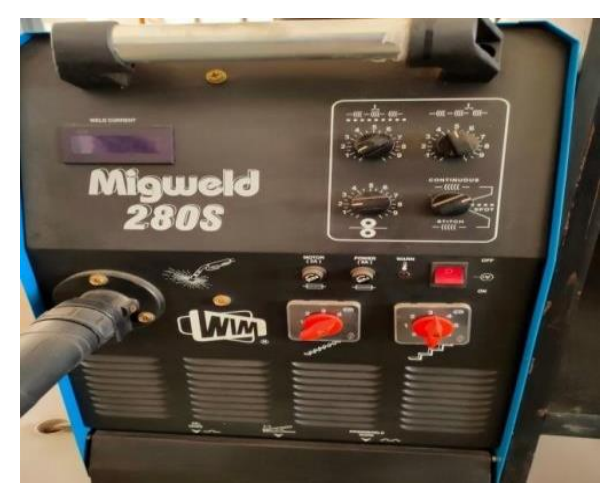

Figure.1 MIG welding machine

Figure.1 is $280 \mathrm{~S}$ model MIG welding machine by WIM Malaysia produced in 2010, which operates in four different course voltages and eight different fine voltages. Weld wire feed rates can be adjusted to nine different levels, allowing for three different weld operations: continuous, spot, and stitch. 
Table.1 Specification of MIG machine

\begin{tabular}{|c|c|}
\hline Main supply & 3 -phase 50/60 Hz \\
\hline Voltage & $380 \mathrm{~V}-415 \mathrm{~V}$ \\
\hline Max input current & $24 \mathrm{~A}$ \\
\hline Output rating & $19 \mathrm{~V}-39 \mathrm{~V}$ \\
\hline Open circuit voltage & $4-0 \mathrm{~A}-280 \mathrm{~A}$ \\
\hline Welding range 50-210A & $1-20 \mathrm{~m} / \mathrm{min}$ \\
\hline Wire feeding speed & IPS21 \\
\hline Degree of protection & $\mathrm{H} 180 \mathrm{OC}$ \\
\hline Insulation class & \\
\hline
\end{tabular}

\section{Mig Welding Shielding Gas - Carbon Dioxide (CO2)}

$\mathrm{CO} 2$ is the only of the shielding gases that available in the market easily and low cost compared to the other inert gases, which is advantageous when welding dense materials, which forms good welding atmosphere and produce less spatter and stable.

\section{Weld Wire}

ER70S-6 is of diameter of $0.08 \mathrm{~mm} \varnothing$ is a wire with a higher concentration of deoxidizers for welding steels. Compared to other carbon steel cables, ( $\mathrm{Mn} \& \mathrm{Si}$ ) This wire can be used to weld steels that have a mild amount of scale or rust. 
Table.2 Chemical composition of weld wire ER70s-6

\begin{tabular}{|l|l|l|l|l|l|l|l|l|}
\hline $\mathrm{C}$ & $\mathrm{Mn}$ & $\mathrm{Si}$ & $\mathrm{Cr}$ & $\mathrm{Mo}$ & $\mathrm{V}$ & $\mathrm{P}$ & $\mathrm{S}$ & $\mathrm{Cu}$ \\
\hline 0.08 & 1.45 & 0.98 & 0.05 & 0.01 & 0.012 & 0.010 & 0.010 & 0.04 \\
\hline
\end{tabular}

Table.3 Mechanical properties welding wire

\begin{tabular}{|l|l|l|}
\hline 1 & Tensile Strength & 70,000 psi min \\
\hline 2 & Yield Strength & 60,000 psi min \\
\hline 3 & Elongation Figure.2 Weld wire fitted in MIG & $27 \%$ \\
\hline
\end{tabular}

\section{Nozzle}

A nozzle is tube like structure used to control the flow of the weld wire in the metal arc welding machine. In project we used $0.08 \mathrm{~mm}$ nozzle for our welding machine which made up of brass.

\section{Selecting the Parameters}

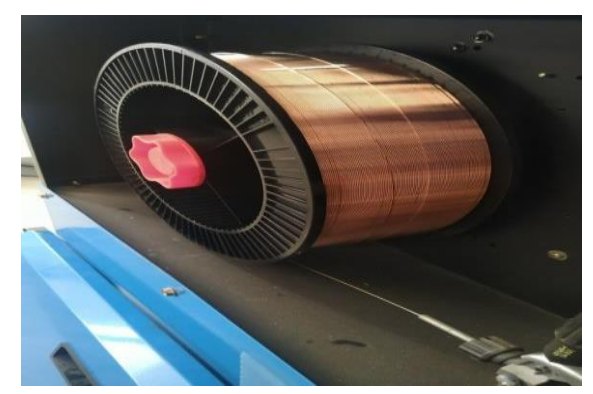

By changing the parameter, we can change the quality of fabrication of the product, so we should choose wisely the parameters before the fabrication of the product. Course voltage, fine voltage, and feed rate were the parameters chosen for research. Table.4 shows the testing of sample at different parameters. 
Table.4 Welding parameters testing

\begin{tabular}{|c|c|c|c|c|}
\hline S.no & Voltage(Course) & Voltage (Fine) & Track speed & Feed rate \\
\hline 1 & 4 & 1 & 3 & 1 \\
\hline 2 & 4 & 2 & 3 & 1 \\
\hline 3 & 4 & 3 & 3 & 1 \\
\hline 4 & 4 & 4 & 3 & 1 \\
\hline 5 & 4 & 5 & 3 & 1 \\
\hline 6 & 4 & 6 & 3 & 1 \\
\hline 7 & 4 & 7 & 3 & 1 \\
\hline 8 & 4 & 8 & 3 & 1 \\
\hline 9 & 3 & 1 & 3 & 2 \\
\hline 10 & 3 & 2 & 3 & 2 \\
\hline 11 & 3 & 3 & 3 & 2 \\
\hline 12 & 3 & 4 & 3 & 2 \\
\hline 13 & 3 & 5 & 3 & 2 \\
\hline 14 & 3 & 6 & 3 & 2 \\
\hline 15 & 3 & 7 & 3 & 2 \\
\hline 16 & 3 & 8 & 3 & 2 \\
\hline 17 & 4 & 1 & 3 & 3 \\
\hline 18 & 4 & 2 & 3 & 3 \\
\hline 19 & 4 & 3 & 3 & 3 \\
\hline 20 & 4 & 4 & 3 & 3 \\
\hline 21 & 4 & 5 & 3 & 3 \\
\hline 22 & 4 & 6 & 3 & 3 \\
\hline
\end{tabular}




\begin{tabular}{|c|c|c|c|c|}
\hline 23 & 4 & 7 & 3 & 3 \\
\hline 24 & 4 & 8 & 3 & 3 \\
\hline 25 & 4 & 1 & 3 & 4 \\
\hline 26 & 4 & 2 & 3 & 4 \\
\hline 27 & 4 & 3 & 3 & 4 \\
\hline 28 & 4 & 4 & 3 & 4 \\
\hline 29 & 4 & 5 & 3 & 4 \\
\hline 30 & 4 & 6 & 3 & 4 \\
\hline 31 & 4 & 7 & 3 & 4 \\
\hline
\end{tabular}

From the testing and Figure.3, we concluded that feed rate of four and course voltage of four and fine voltage of five (29), six (30), seven (31), eight (32) are given good result. After go throwing the result, we selected course voltage four (4), fine voltage six (6) and feed rate three (3) for building the wall like structure.

\section{FABRICATION OF PRODUCT}

Figure.3 Good bead structure selected from sample weld plate Machine Setup

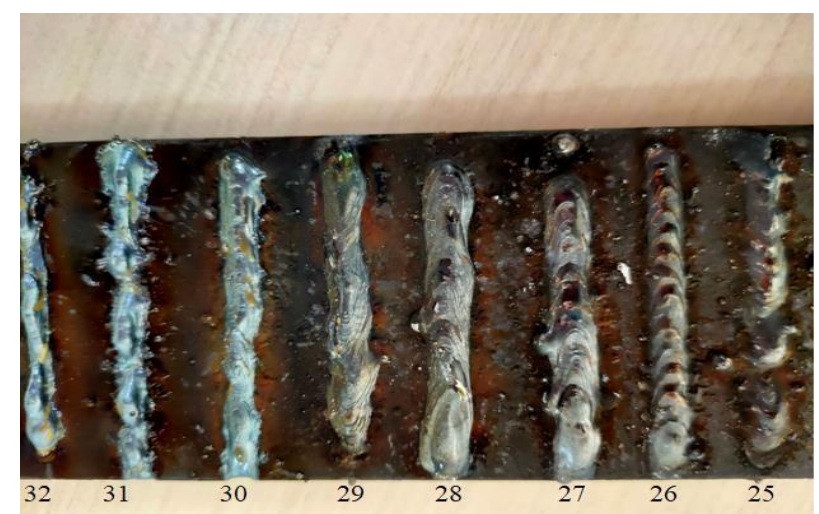

When computer numerically operated machining was introduced, it provided a quicker and more effective way of machining complex elements. Typical CNC gears aid with translation 
in three axes; multi axis machines also assist with rotation around one or a few axes. In industry, 5-axis machines are widely used to convert work pieces linearly along three axes (usually x, y, and z). Many Computer Aided Manufacturing software structures are now available to direct multi-axis machining, including software that can turn three-axis interface paths into five-axis tool paths on the switch. Prior to the invention of Computer Aided Manufacturing, moving records from layout to manufacturing often necessitated a significant amount of guide labour, which resulted in errors.

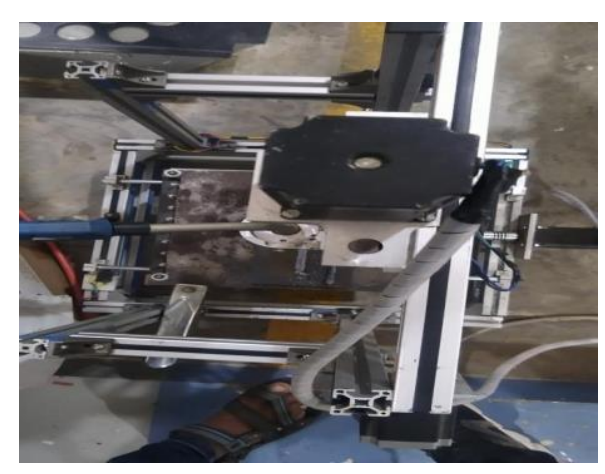

Figure.4 CNC machine

\section{Working}

In our project, some electrical components such as a driver, switch mode power supply, and mach3 controller, as well as mach3 software, are used to allow the CNC functioning. $\mathrm{X}$ axis movement is assigned for bed movement where the working product will be manufactured, $\mathrm{Y}$ axis movement is assigned for sliding action in a horizontal direction where the tool holder like Metal inert gas welding (MIG) torch will be mounted, $\mathrm{Z}$ axis movement is assigned for vertical movement of welding torch along the smooth rod meanwhile it is connected with lead screw, where the material is added layer by layer process. The three axis movements are controlled with the help of mach3 controller and it is integrated with mach3 software then it is connected to driver to actuate the stepper motor in order to control the three-axis movement. Using this arrangement, we built a wall with dimensions of $120 \mathrm{~mm}$ in length, $10 \mathrm{~mm}$ in width, and $100 \mathrm{~mm}$ in height. The course voltage is four, the fine voltage is 
six, and the feed rate is six on the MIG welding machine.

\section{Experimental Procedure}

Wire arc additive manufacturing process consists of welding machine, CNC machine, weld wire, nozzle and shielding gas. The weld wire used for the fabrication is ER70S-6 which is mild steel wild wire. The CNC machine runs using mach3 software and controlled by mach3 controller, which help to convert the $\mathrm{G}$ code for the fabrication process digital signal for the CNC operation. Nozzle used is of $0.8 \mathrm{~mm}$ diameter and made of brass.CO2 is used as shielding gas for good welding. The base material use was mild steel, the gap between the nozzle and the base plate is $15 \mathrm{~mm}$ to have adequate space for welding, which will help to reduce the overlap. The CNC programs for welding of 25 layers are written imported to mach3 software. The MIG welding specifications are set according to the Table.5 readings. The welding operation is done in single direction and in perpendicular angle there were time gap 15 seconds for each layer which will allow good depositing of the wed material and helps in the cooling process. By following this procedure, the wall is builded.

Table.5 Selected parameters for fabrication

\begin{tabular}{|c|c|c|c|c|}
\hline S.no & Voltage (course) & Voltage (fine) & Feed in CNC & Wire Feed rate \\
& & & machine & \\
\hline 1 & 4 & 6 & $30 \mathrm{~mm} / \mathrm{s}$ & 4 \\
\hline
\end{tabular}

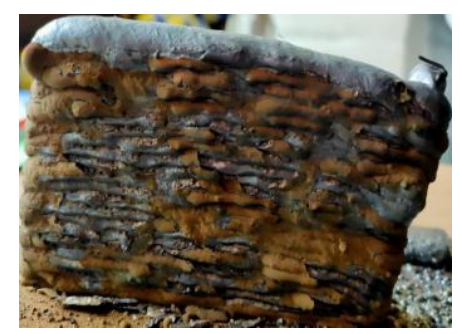

Figure.5 Fabricated product 


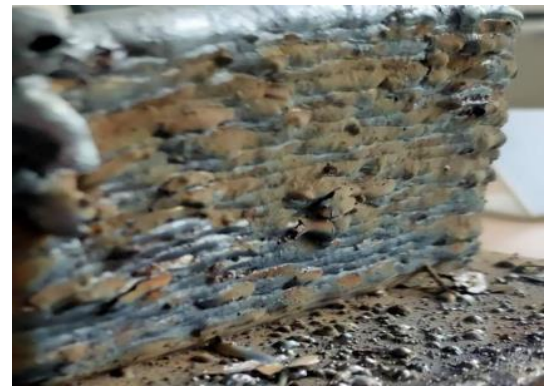

Figure.6 Side view of the product

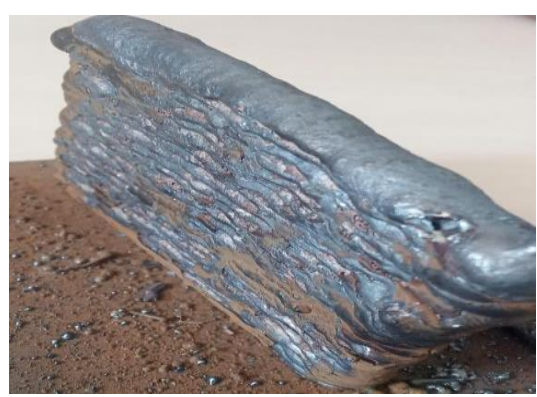

Figure.7 Top view of the product

Figure. 5 is the fabricated product of dimension $120 \mathrm{~mm} 10 \mathrm{~mm} \mathrm{100m} \mathrm{((length,} \mathrm{breath,} \mathrm{height)}$ which is made by welding deposition of weld wire ER70S-6. Figure.6 \& Figure.7 shows the different sides for the fabricate product.

\section{POST PROCESSING AND TESTING}

\section{Post Processing}

A hand cutter machine was used to machine all specimens for mechanical properties examination, which were then ground and polished. The microstructure of the specimen was examined using an optical microscope. In a Rockwell hardness tester, the hardness was measured in a straight line from bottom to top.

\section{Microstructure Analysis}

Cutting machines were used to collect samples from the settled walls in longitudinal and transversal directions for micro structural analysis. Following surface polishing, samples were polished with $600,800,1000,1200,1500$, and 2000 grade emery papers. Methanol was used as an etchant. Photos were captured with appropriate magnifications using an optical microscope. The microstructures of ER70S-6 mild steel material builded by welding and dimension of $30 \mathrm{~mm}, 10 \mathrm{~mm}$, and $10 \mathrm{~mm}$ specimen sample are made microstructure analysis using optical microscope. The microstructure analyses were carried out in three specimens at different position. The magnification of 50 microns is done. 

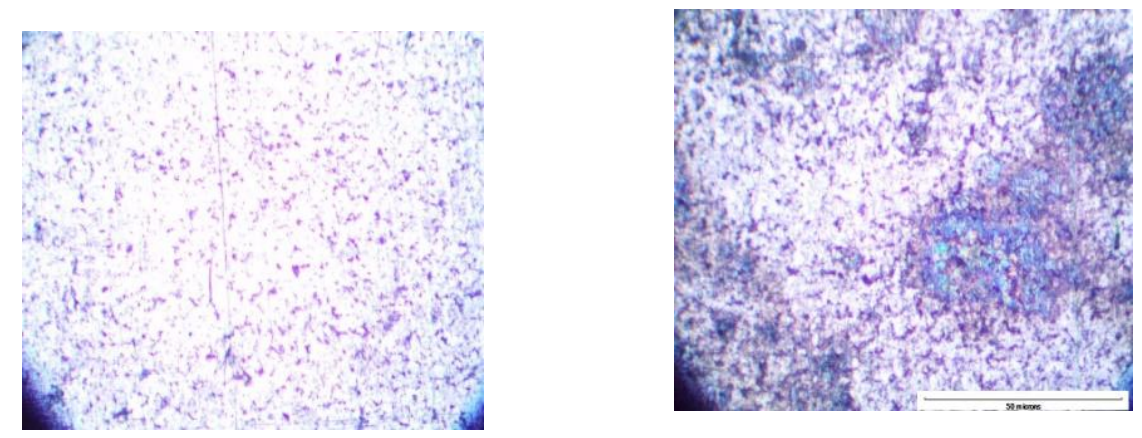

Figure.8 Specimen 1

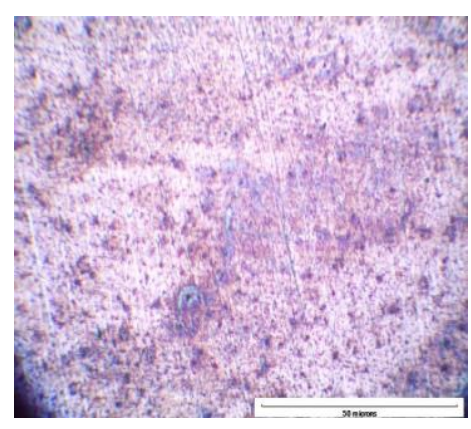

Figure.10 Specimen 3
Figure.9 Specimen 2

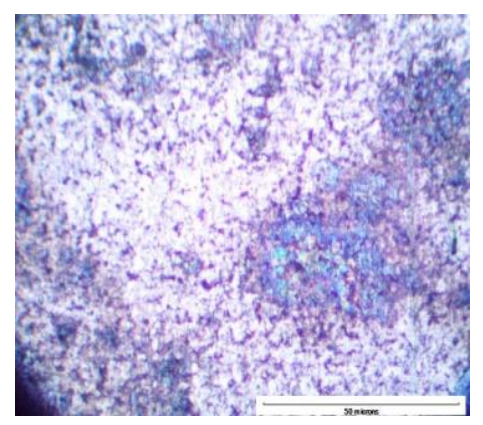

Figure.11 Specimen 4

From the above figures analysis of ER70S-6 wed wire build material shows good pearlite content which can been seen as black lines and also have ferrite content can be seen as white lines. This both pearlite and ferrite content is evenly distributed in all the specimen, because of good deposition.

\section{Hardness Testing}

The hardness values measured on two different positions on same piece. From the testing we get thee average hardness is 76 for overall specimen. The average hardness of specimen 1 is 78 and the average hardness of the specimen 2 is 78 . Table. 6 shows the specification of Rockwell hardness testing machine model RAB-1. In this tester use diamond and ball as indentors for testing, in this test for mild steel we use diamond indentor and load of is $150 \mathrm{kgf}$ in two different position for accurate value. 
Table.6 Specification of Hardness machine

\begin{tabular}{|c|c|}
\hline Max test height & $225 \mathrm{~mm}$ \\
\hline Depth of throat & $150 \mathrm{~mm}$ \\
\hline Indentors & Diamond 120, Ball(1/16Ø), (2.5mmØ) \\
\hline Maximum Depth to Elevating & $220 \mathrm{~mm}$ \\
\hline
\end{tabular}

Specimen piece: 1

Table.7 Hardness testing of specimen 1

\begin{tabular}{|c|c|c|}
\hline Position & Load & Hardness Value in kgf \\
\hline 1 & 150 & 85 \\
\hline 2 & 150 & 63 \\
\hline & Average & $\mathbf{7 4}$ \\
\hline
\end{tabular}

Specimen piece: 2

Table.8 Hardness testing of specimen 2

\begin{tabular}{|c|c|c|}
\hline Position & Load & Hardness Value in kgf \\
\hline 1 & 150 & 96 \\
\hline 2 & 150 & 61 \\
\hline & Average & $\mathbf{7 8}$ \\
\hline
\end{tabular}

From the testing we came to conclusion that hardness value is not uniform in the specimen, this all due to the layer-by-layer deposition, which done by welding the weld wire ER70S-6. Due to welding the microstructure value differs at different place but this does not affect the quality of product, Since the deviation in the value is very small. The overall value founded 
is higher than conventional casting process and product fabricated by this process shows good mechanical properties.

\section{CONCLUSION}

Now a day the usage Wire arc additive manufacturing process in manufacturing sector is increasing in large scale due to its quality of product and less waste of material during the fabrication process. In small scale production of complex product this technology is widely used. In this project we used ER70S-6 as weld wire of $0.8 \mathrm{~mm}$ diameter for fabrication of the product using self-made $\mathrm{CNC}$ machine which runs on mach3 software and with help MIG welding machine, $\mathrm{CO} 2$ is used as shielding gas. From this fabricated material microstructure and mechanical test are done.

Microstructure analysis: The microstructure analysis of the specimen shows the good quantity of pearlite and ferrite in the specimen compared to casting made product, this all due to the direct deposition of the material.

Mechanical test: Hardness test of mild steel component made from ER70S-6 have higher hardness value compared to normal product, even though their little deviation in the hardness value due change in microstructure.

\section{REFERENCES}

Wu B, Pan Z, Ding D, Cuiuri D, Li H, Xu J, Norrish J. 2018. A review of the wire arc additive manufacturing of metals: properties, defects and quality improvement. Journal of Manufacturing Processes. Oct 1;35:127-39.

Cunningham CR, Wikshåland S, Xu F, Kemakolam N, Shokrani A, Dhokia V, Newman ST. 2017 Cost modelling and sensitivity analysis of wire and arc additive manufacturing. Procedia Manufacturing. Jan 1;11:650-7.

Zhang Z, Sun C, Xu X, Liu L. 2018 Surface quality and forming characteristics of thin-wall aluminium alloy parts manufactured by laser assisted MIG arc additive manufacturing. International 
Journal of Lightweight Materials and Manufacture. Jun 1;1(2):89-95.

Ding D, Pan Z, Cuiuri D, Li H. 2015 A multi-bead overlapping model for robotic wire and arc additive manufacturing (WAAM). Robotics and Computer-Integrated Manufacturing. Feb 1;31:10110.

Rodrigues TA, Duarte V, Avila JA, Santos TG, Miranda RM, Oliveira JP.2019 Wire and arc additive manufacturing of HSLA steel: Effect of thermal cycles on microstructure and mechanical properties. Additive Manufacturing. 2019 May 1;27:440-50.

Nagamatsu H, Sasahara H, Mitsutake Y, Hamamoto T. 2020 Development of a cooperative system for wire and arc additive manufacturing and machining. Additive Manufacturing. Jan $1 ; 31: 100896$.

Panchagnula JS, Simhambhatla S. 2018 Manufacture of complex thin-walled metallic objects using weld-deposition based additive manufacturing. Robotics and Computer-Integrated Manufacturing. Feb 1;49:194-203.

Karunakaran KP, Suryakumar S, Pushpa V, Akula S. 2009 Retrofitment of a CNC machine for hybrid layered manufacturing. The International Journal of Advanced Manufacturing Technology. Dec 1;45(7-8):690-703.

Karunakaran KP, Suryakumar S, Pushpa V, Akula S. 2010 Low cost integration of additive and subtractive processes for hybrid layered manufacturing. Robotics and Computer-Integrated Manufacturing. Oct 1;26(5):490-9.

Williams SW, Martina F, Addison AC, Ding J, Pardal G, Colegrove P. 2016 Wire+ arc additive manufacturing. Materials Science and Technology. May 2;32(7):641-7.

Sun R, Li L, Zhu Y, Guo W, Peng P, Cong B, Sun J, Che Z, Li B, Guo C, Liu L. 2018 Microstructure, residual stress and tensile properties control of wire-arc additive manufactured 2319 aluminum alloy with laser shock peening. Journal of Alloys and Compounds. May 30;747:255-65. 
Ryan EM, Sabin TJ, Watts JF, Whiting MJ. 2018 The influence of build parameters and wire batch on porosity of wire and arc additive manufactured aluminium alloy 2319. Journal of Materials Processing Technology. 2018 Dec 1;262:577-84.

Dirisu P, Supriyo G, Martina F, Xu X, Williams S. 2020 Wire plus arc additive manufactured functional steel surfaces enhanced by rolling. International Journal of Fatigue. Jan 1;130:105237.

Miao Q, Wu D, Chai D, Zhan Y, Bi G, Niu F, Ma G. 2020 Comparative study of microstructure evaluation and mechanical properties of 4043 aluminum alloy fabricated by wire-based additive manufacturing. Materials \& Design. Jan 15;186:108205.

Karunakaran R, Ortgies S, Tamayol A, Bobaru F, Sealy MP. 2020 Additive manufacturing of magnesium alloys. Bioactive materials. Mar 1;5(1):44-54.

Wang JF, Sun QJ, Wang H, Liu JP, Feng JC. 2016 Effect of location on microstructure and mechanical properties of additive layer manufactured Inconel 625 using gas tungsten arc welding. Materials Science and Engineering: A. 2016 Oct 31;676:395-405.

Xu X, Ganguly S, Ding J, Guo S, Williams S, Martina F. 2018 Microstructural evolution and mechanical properties of maraging steel produced by wire+ arc additive manufacture process. Materials Characterization. Sep 1;143:152-62.

Suryakumar S, Karunakaran KP, Bernard A, Chandrasekhar U, Raghavender N, Sharma D. 2011 Weld bead modeling and process optimization in hybrid layered manufacturing. ComputerAided Design. Apr 1;43(4):331-44.

Peddiraju VC, Pulapakura KK, Jagadeesh DS, Athira KS, Gudur S, Suryakumar S, Chatterjee S. 2020 Weld deposition of nickel on titanium for surface hardening with Ti-Ni-based intermetallic compounds. Materials Today: Proceedings. 2020 Jan 1;27:2096-100.

Chandrasekaran S, Hari S, Amirthalingam M. 2020 Wire arc additive manufacturing of functionally graded material for marine risers. Materials Science and Engineering: A. 2020 Aug 5;792:139530. 